\title{
Higher education: discipline or field of study?
}

\section{Malcolm Tight $^{1}$}

Received: 9 June 2020 / Accepted: 11 August 2020 / Published online: 18 August 2020

(C) The Author(s) 2020

\begin{abstract}
Higher education, or more strictly higher education studies, is sometimes referred to as a discipline, though it is more often referred to as a field, sector or area for study. But what is a discipline and does higher education studies, at its current state of development, qualify as one? This article re-considers these matters and comes to some conflicting conclusions. The issue of whether higher education studies is, or is not, a discipline should probably, therefore, be regarded as still open for debate.
\end{abstract}

Keywords Discipline $\cdot$ Field $\cdot$ Higher education $\cdot$ Higher education research

\section{Introduction}

Higher education studies has grown rapidly across the globe during the last few decades. Thus, one recent study identified 86 specialist English language academic journals focusing exclusively on higher education that between them published over 16,000,000 words in 2016 alone (Tight 2018). As a focus for research, then, higher education studies could be argued to be maturing; but is it, as some have argued, a discipline? The purpose of this article is to review the arguments for and against such a view and seek to reach a measured conclusion.

This is not, of course, a new debate; one substantive American examination of the question - which concluded that higher education studies was a field of study rather than a discipline dates back nearly 50 years (Dressel and Mayhew 1974). Others have addressed the question more recently (e.g. Fulton 1992, Harland 2012, Macfarlane and Grant 2012). Another review, and one that extends internationally beyond the American context, seems timely.

Note that I am deliberately using the term 'higher education studies' here rather than just 'higher education'. Higher education is the sector of activity that is being researched, but the additional word in 'higher education studies' is necessary to avoid confusion. If it is a discipline, we should call it 'higher education studies' or something like that. If it remains simply a focus for research, 'higher education' will do fine.

Malcolm Tight

m.tight@lancaster.ac.uk

1 Department of Educational Research, Lancaster University, Lancaster LA1 4YL, UK 
The article will proceed by first considering if and why it matters whether higher education studies is a discipline or not. The literature on the nature of disciplines (and fields) is then reviewed. Other research foci which, like higher education, have claimed disciplinary status with more or less success - will also be identified. The relation between higher education studies and educational studies will be examined, and the case for and against the former achieving disciplinary status will be carefully reviewed. Finally, some conclusions will be reached.

\section{Why does this matter?}

We may, of course, immediately question if and why it matters whether higher education studies is a discipline or not. Or, in other words, is 'discipline' more than simply a label? Are there any positive practical consequences that would come if higher education studies was recognised and accepted as a discipline? And, if it does matter, to whom does it matter: those researching higher education, the academy as a whole or the wider society beyond?

It is the case, as we shall see, that some higher education researchers seek to claim disciplinary status - for the whole of higher education studies or just the particular part of it that they work in - so it clearly matters to them, at least to some extent. Higher education researchers are, as we shall also see, by no means unique in making such claims, which have been regularly made by practitioners in particular fields throughout the history of the academy. Clearly, then, there is some perceived benefit in being a discipline, even if - as with many terms in academia - the word 'discipline' is used both loosely and in varied ways.

Widespread recognition of higher education studies as a discipline would undoubtedly give it more status, at least in academic circles. The academy is, of course, highly status conscious indeed, it might be argued that it is an environment in which status matters as least as much as funding (compare, for example, the attitude toward any relatively new discipline including in its name the suffix 'studies' and that towards, say, philosophy or physics) - so such recognition would be hard won and conditional, and thus worth having. It would not, however, have any great impact on the existing disciplinary pecking order, where the pure sciences and medicine clearly rule the roost, so the status of higher education studies would remain relatively low.

Recognition of higher education studies as a discipline beyond the academy, in the wider society and economy, would likely be even less significant. While greater acknowledgement of the work of higher education researchers in understanding and enhancing the diverse operations of higher education would be welcomed, whether they are seen as belonging to a discipline or researching a field is of little relevance outside academe. What matters is fruitful engagement with government, industry and other interested parties or stakeholders.

If, however, recognition of higher education studies as a discipline is denied, the practical business of higher education studies would arguably still continue. But it would remain relatively easier for others in the academy and beyond to ignore the findings of higher education research, as they commonly do so now, and to instead advance their own - anecdotal, poorly evidenced or wholly unevidenced - opinions. Higher education is, after all, a field that is, unusually, researched by those within it, and on which everyone else working within, or with experience of, it has their own opinions (or, as Harland (2012) put it, it is 'open access').

The status of higher education studies - as a discipline or a field of study - does, therefore, matter, and not only to higher education researchers, but also to the academy as a whole, though perhaps not as much as some might wish. So the question is worthy of more exploration. 


\section{The nature of disciplines (and fields)}

It is a common characteristic of those writing about the meaning and nature of disciplines to start etymologically (e.g. Shumway and Messer-Davidow 1991, Turner 2006). Following this approach, the New Shorter Oxford English Dictionary offers one definition of discipline as 'a branch of learning or scholarly instruction' (1993, p. 685) alongside a series of other related meanings concerning correction, religion, training, medicine and the military. That, however, seems overly simple or general, and might be applied to just about any academic activity, or to learning as a whole.

Another short, but more modern, definition is provided by Lawn and Keiner, who state 'Academic disciplines can be seen as multi-dimensional socio-communicative networks of knowledge production' (2006, p. 158). This makes their broad purpose, knowledge production rather than just instruction, clearer, as well as their general mode of operation (i.e. communication). It also makes them sound complex, but without revealing any of that complexity.

A fuller definition is offered by Squires (1992, p. 202, original emphases):

disciplines can be defined in terms of three dimensions: (i) what they are about (object); (ii) their stance toward that object, in terms of a concern with knowing, doing or being; and (iii) the extent to which they are operating in a normal, reflexive or philosophical mode. The first of these dimensions manifests in the content, topics or problems which are addressed; the second in the methodologies, techniques and procedures which are used; and the third in the extent to which the discipline treats its own nature as the subject of reflexive analysis.

This usefully offers rather more indicative detail on how disciplines work in practice.

Delving more deeply, Krishnan (2009) considers a range of philosophical, anthropological, sociological, historical and management perspectives on disciplines. While recognising that not all disciplines need demonstrate all of these features, he argues that:

A general list of characteristics would include: 1) disciplines have a particular object of research (e.g. law, society, politics), though the object of research may be shared with another discipline; 2) disciplines have a body of accumulated specialist knowledge referring to their object of research, which is specific to them and not generally shared with another discipline; 3 ) disciplines have theories and concepts that can organise the accumulated specialist knowledge effectively; 4) disciplines use specific terminologies or a specific technical language adjusted to their research object; 5) disciplines have developed specific research methods according to their specific research requirements; and maybe most crucially 6), disciplines must have some institutional manifestation in the form of subjects taught at universities or colleges, respective academic departments and professional associations connected to it. (p. 9)

While more comprehensive, this is not dissimilar to Squires' presentation, with both leading with object, and Squires' notion of stance broken down by Krishnan into theory, terminology and method. Squires does not, however, specifically mention accumulated knowledge or institutional manifestation (at least not in his definition), while Krishnan does not include Squires' idea of disciplinary reflexivity.

The last of the characteristics identified by Krishnan, which he suggests may be the most crucial, is probably the most obvious when we think about disciplines: the whole paraphernalia of departments, chairs, learned societies, specialised academic journals, conferences, interest 
groups and so forth. The other characteristics which Krishnan identifies - object, accumulated knowledge, theories, terminologies and methods - are, however, of critical importance, if perhaps harder to pin down.

In their earlier study of the topic, Dressel and Mayhew (1974) came up with a list of criteria which was similar to, but slightly more extensive than, Krishnan's:

One commonly accepted criteria of a discipline is a general body of knowledge... A corollary of this first criterion is that a discipline should possess both a specialized vocabulary and a generally accepted basic literature... some generally accepted body of theory and some generally understood techniques for theory testing and revision... a generally accepted body of consistently applied techniques of analysis or a generally agreed-upon methodology... recognized techniques for replication and revalidation of research and scholarship... trappings which symbolize their status as disciplines scholarly associations... journals... Most disciplines have a recognized sequence of experiences for the preparation of scholars and research workers... But of all criteria of a discipline, possibly the key is a sense of sequence which enables scholars to predict where they should look next. (pp. 3-6)

This list is particularly interesting, both because it was put forward to assess the status of higher education studies as a discipline, but also because it includes criteria not directly addressed in the other frameworks: replication and revalidation, preparatory experiences and the notion of where to look next.

The literature on disciplines emphasizes, amongst other matters, that they are not static entities - indeed, their historical development is widely discussed (e.g. de Ridder-Symoens 1992, Shumway and Messer-Davidow 1991) - and nor are they constant across the globe. Physics, psychology and political science, for example, may be pursued in distinctively different ways in China, Russia, Saudi Arabia and the USA.

We may recognise types of discipline, with the fourfold distinction between soft/hard and pure/applied that originated with Biglan (1973a, 1973b; see also Becher 1989, Becher and Trowler 2001) still being widely applied. Hard disciplines (e.g. physics, pharmacy) are those with an agreed paradigm and where knowledge is cumulative; soft disciplines (e.g. history, sociology), by contrast, are more contested and less cumulative. Pure/applied concerns the degree to which research is directed towards understanding something that interests the researcher or towards solving practical problems. Chemistry and mathematics, for example, would be (primarily) classified as pure disciplines, engineering and law as applied.

And then there is the distinction which we recognised in the introduction between a discipline and a focus - or field - of (or for) study. Or is it fields? Thus, Macfarlane and Grant (2012, p. 621) argue that 'the study of higher education may be understood as a multiple series of intersecting cognate fields rather than one that is discrete', while Clegg (2012, p. 667) goes further in identifying the three intersecting or overlapping fields of 'research into higher education, academic development and disciplinary teaching research' as constituting the foci for higher education studies.

Krishnan's first characteristic of a discipline, its object of research, is fairly synonymous with what we mean here by field, suggesting that fields are components of disciplines. Thus, higher education is clearly a field - or a series of fields - for research, but higher education studies might claim to be a discipline. 
We may also, of course, range both above and below disciplines. Taking the latter direction first, disciplines are typically viewed as being composed of numerous sub-disciplines, such that, while most researchers would readily identify with a particular discipline (e.g. history, physics), their real allegiance would be to the sub-discipline (e.g. medieval France, quantum physics) they research and/or teach. Sub-disciplines may become fully fledged disciplines as they develop (e.g. as with the emergence of statistics from mathematics). Thus, in the particular case we are discussing here, the issue may be whether higher education studies is still a sub-discipline of educational studies, or has developed sufficiently far to become a discipline in its own right.

Looking above, or beyond, disciplines, there are all the recurrent arguments which suggest that real, complex issues or problems (e.g. climate change, poverty) can only be addressed through interdisciplinary research, probably outside of higher education institutions at least as much as within them (Gibbons et al. 1994). In addition to interdisciplinarity there are a whole range of related terms, of which multidisciplinarity and transdisciplinarity are probably the most common (Davies and Devlin 2010). Given the evident interest in studying aspects of higher education across the entire range of disciplines, we might, therefore, seek to recognise higher education as an interdisciplinary field, or fields, for research.

In short, though we may think of academic disciplines as well established and monolithic, they are really rather amorphous, fractured and transitory entities waiting for events, discoveries or new interpretations to transform them; perhaps only slowly but sometimes almost overnight. The map of knowledge, if we think of it like that, is being continually re-drawn (Abbott 2001, Collins 1998).

In this context - and thinking in particular about whether higher education studies might qualify as a discipline or not - it is striking how this question echoes across the whole of academe. Thus, some brief bibliographic searches were able to identify a huge range of fields of study that were, at different times, seeking or arguing for disciplinary status: e.g. American studies (Pearce 1957), clinical nutrition (Cardenas 2016), cultural studies (During 2006), dental hygiene (Cobban et al., 2007), English (Randel 1958), human resource development (Chalofsky 2007), innovation studies (Fagerberg and Verspagen 2006), international business (Michailova and Tienari 2014), nurse education (Findlow 2012), planning (Davoudi and Pendlebury 2010), religion (Nemetz 1959), statistics (Minton 1983) and women's studies/gender studies (Rollman, 2013, Safarik 2003). There are doubtless many more such accounts.

As the dates for the articles identified suggest, these debates have been going on for a long time. In a general sense, there have been such debates ever since universities were founded, but they have undoubtedly increased in recent times as knowledge has both ballooned and fractured.

\section{Is higher education studies a discipline?}

\section{Is educational studies a discipline?}

As a preliminary to considering whether higher education studies is a discipline, it is worth spending a little time posing the same question for educational studies, which might, as we have argued, be seen as its parent discipline. Here are two somewhat contrasting perspectives from different parts of the globe. First, from Sweden, Sundberg (2004) confidently demarcates 
the period in which what he terms 'educational science' (note the use of the word 'science' to provide the emergent discipline with added strength) achieved disciplinary status:

Educational science became firmly institutionalised and established as a discipline in Sweden during the golden age of educational reform and the radical breakthrough of comprehensive schooling in the 1950s and 1960s. It is in this period that Pedagogik was separated from psychology and sociology separated from philosophy. (p.394)

Second, and alternatively, from the very different context of India, Sarangapani (2011) indicates that, while some may view education as a discipline, others strongly challenge this position:

Many of us who conduct research on and teach education in institutes of higher education have been socialised to think of education as a discipline. Yet not only do we find this status disputed, but we also frequently encounter challenges to our claims as experts and to the form and structure of our discourse, both by members of the public and, more disconcertingly, by fellow academics from other disciplines. (p. 67)

Indeed, one might go further in recognising that the status of educational studies as a discipline is also challenged from within education.

Her analysis leads Sarangapani, following Biglan, Becher and others, to apply the term 'soft discipline' to education. She notes that education 'is non-paradigmatic and it is wholly 'applied' in the sense of being concerned with a practice', and 'it does not have distinct/ distinguishing theories that are unique to it' (pp. 72-73). It is, therefore, in her view, missing at least two of the characteristics of a discipline identified by Krishnan (2009).

Furlong (2013), also holding to the idea of educational studies as a discipline, provides a useful summary of the position, particularly in the UK:

As would be true of any discipline, trying to understand the discipline of education means taking into account its epistemological as well as its sociological dimensions... education presents a contradictory picture here. Sociologically, it is and always has been strong in key respects. It is large, complex and strategically important and despite recent policy challenges, particularly in England, it remains relatively well embedded in the university system. At the same time, it is epistemologically weak, largely because of important and unresolved questions about the nature of educational knowledge. It is these difficulties that, despite its size, have served constantly to undermine its position within the academy. (p. 13)

These difficulties have not, however, prevented several sub-disciplines, or specialisms, of educational studies from seeking to claim disciplinary status in their own right; including art education (Logan 1963), comparative education (Heath 1958), general education (Uljens 2001) and even teaching (Loughran 2009).

What then of higher education studies? I will use the six characteristics (or criteria) identified by Krishnan as a framework for assessing the claims of higher education studies to be a discipline. These offer a useful heuristic for attempting such a judgment.

\section{1) A Particular Object of Research.}


This is perhaps the simplest of the six characteristics to satisfy. It is arguably also the weakest, as it is difficult to imagine any field, discipline or sub-discipline of research that did not have a particular object. What we are talking about here is that higher education studies should have a focus.

Obviously, higher education studies focuses on higher education; that is the object of the research or study. Conversely, any research or study that focuses on higher education may be deemed to be higher education studies, however its investigators may classify it, even if it takes place within, for example, a department of politics, accounting or chemistry (see the later discussion of institutional manifestation).

Higher education is clearly a worthy object for research and study. To take the UK as an example, at the present time the equivalent of about $4 \%$ of the population are registered as students in higher education and about $1 \%$ work in higher education in some capacity (fulltime or part-time: www.hesa.ac.uk). Overall, then, this is a substantial enterprise, and, at the level of individual universities and colleges, most are major employers and traffic foci in the towns and cities in which they are located. Looked at globally, the size of the enterprise is quite staggering:

Postsecondary education is now a major enterprise worldwide. Massification has dramatically increased global enrollments; there are more than 170 million students enrolled in 2013, with expansion continuing worldwide. This growth has transformed higher education institutions and systems, and there are now more than 18,000 universities worldwide. (Altbach 2014, p. 11)

\section{2) A Body of Accumulated Specialist Knowledge.}

It is also clear that, over the years, a significant body of specialist knowledge relating to higher education has been accumulated through higher education research. We have already quoted the estimate of over 16,000,000 words having been published in 86 specialist English language academic journals focusing exclusively on higher education in 2016 alone (Tight 2018). That figure increases year by year and does not include other sorts of journals (e.g. education journals, other disciplinary journals) or other types of publications (e.g. books, reports, conference publications), so the true output is much larger than this estimate.

Of course, it may be said that some of this output is repetitive, that a lot of it is small-scale and that it is of variable quality. But these are characteristics of research in general: only a small proportion is truly ground-breaking, large-scale research is very time-consuming and difficult to fund, and most research is not 'world class'.

What is perhaps more concerning about higher education studies is the issue of accumulation, though, again, this could be said of many of the social sciences. Replication and revalidation studies - two of the criteria identified by Dressel and Mayhew (1974) - are vanishingly uncommon in higher education studies, and in educational studies as a whole. Thus, Makel and Plucker (2014) analysed all of the articles published in the then top 100 education journals - which included many higher education journals - but found that only $0.13 \%$ of them were replication studies.

Higher education studies also remains a fragmented area of research. Those focusing on particular topics, or applying particular methodologies or theories, or working in particular 
systems, typically have little to do with others researching higher education, even when they are researching closely related topics (Daenekindt and Huisman 2020, Macfarlane 2012, Shahjahan and Kezar 2013).

However, while the linkages within higher education studies could certainly be improved, that there is a body of accumulated specialist knowledge - or, rather, a series of developing and disparate bodies - cannot be doubted.

\section{3) Theories and Concepts.}

It is when we get to this characteristic that things become more problematic. Thus, an analysis of the output of 17 specialist higher education journals, published in English outside of North America in 2000, concluded:

an examination of the 406 articles found that 104 (25.6\%) made explicit use of theory, that in a further $66(16.3 \%)$ there was some evidence of the use of theory, and that the remaining majority, $236(58.1 \%)$, were wholly a-theoretical. In short - and insofar as the sample examined reflects higher education research practice in general - theoretical engagement would appear to be a minority interest or need amongst higher education researchers. (Tight 2004, p. 400)

Higher education studies - as a field or discipline - will, of course, likely be lacking in organising theories and concepts if most (published) researchers do not even engage with theory.

However, more recent analysis (Tight 2012, 2014) of 15 leading international journals this time including five North American journals - came to more positive conclusions. This analysis was of 567 articles published in 2010:

$470(83 \%)$ of the articles were found to be theoretically explicit, though the extent of engagement was often limited and the level of theory referred to was frequently low.

(Tight 2014, p. 100)

Three main factors seem to largely explain the difference in these findings. First, the inclusion of leading journals from North America - where higher education research has been established for longer - in the sample, which typically expect authors to explicitly address theoretical (and methodological) issues. Second, the restriction of the non-North American sample to a smaller group of 'leading' journals; and, third, the passage of time, with one decade being long enough to significantly raise the quality of articles published in the most competitive, non-North American journals.

The point about the level of theory in use, however, still largely holds. At least two trends can be observed here. First, where better developed and higher-level theories are in use, they tend to be imported from other disciplines or fields and applied to higher education. Examples of such theories include academic literacies (from applied linguistics), activity theory (from psychology), human capital (from economics), institutional diversity (from biological sciences) and managerialism (from management).

There are a few exceptions to this trend, such as communities of practice theory, which arguably developed on the borders of management and education. There are also some examples of what appear to be fairly well-developed higher education theories which, on 
closer inspection, originate elsewhere. This would include both academic drift, which owes a great deal to institutional theory (i.e. institutional isomorphism), and student attrition, which, remarkably, builds on theories of both suicide and employee turnover (from sociology and business studies respectively).

Second, most theories in higher education studies seem to be developed largely from the topic being researched (i.e. in classic grounded theory or inductive fashion); that is, they may be regarded more as concepts than theories. Examples include theorising around the idea of the university, modes of knowledge, problem-based learning, the research/teaching nexus and student engagement. These may be seen as 'native' to higher education studies but involve little more than simple classifications (often dichotomous) or the reification of 'good' practice into a model.

There are a few examples of higher education theories which have developed further to become largely accepted within their sub-fields (or sub-disciplines) of higher education studies. Thus, learning approaches theory, which seeks to categorise (albeit in a quasidichotomous fashion) and explain students' approaches to learning, and, by extension, how these may be altered, has wide acceptance within the academic/educational development community. Interestingly, this theory was substantially developed through the use of phenomenography, perhaps the only research design to have been developed (at least partly) within higher education research.

A second, and more recent, example of widespread acceptance is threshold concepts theory, which argues that, in any discipline, certain concepts are more difficult for some students to understand yet are essential if progress is to be made. This has been taken up widely by higher education practitioners, though arguably rather too widely as almost any curricular element may be identified as a threshold concept.

\section{4) Specific Terminologies.}

This characteristic is, arguably, not as critical as the others identified by Krishnan. After all, all academics - though some more than others - tend to use specific terminologies (or, more pejoratively, jargon). For example, the terms academic drift, modes of knowledge and threshold concepts, amongst others, have already been used in this article, each of which would have a particular meaning to other higher education researchers, but probably not to researchers or others outside of this field.

It would be difficult to argue, however, that higher education studies has its own developed technical language, like other more established disciplines such as physics or psychology. Rather, higher education researchers have adopted a great deal of terminology - as well as theoretical perspectives - from other disciplines, particularly across the social sciences but more widely as well. More generally, it is probably the case that higher education researchers would have relatively little difficulty explaining their work to researchers in established disciplines, whereas the reverse would likely be rather more problematic.

\section{5) Specific Research Methods.}

As with theories and concepts, the verdict here would also have to be that higher education researchers have been responsible for little in the way of methodological development. Rather, they predominantly tend to make use of common social sciences research methods, such as interviews, surveys and documentary analysis. The level of sophistication in analyses varies 
widely, and has a geographical element, with North American-based researchers being much more likely to employ multivariate analysis techniques. Other research methods, such as auto/biographical, observational and conceptual methods, are much less commonly used (or published).

This reliance on the standard social science research methods and methodologies is, however, common to many social research fields, including education in general. Even amongst established social science disciplines, such as human geography, political science and sociology, most research relies on these generic methods. But these established disciplines have also developed their own specialist methodologies, such as geographical information systems and ethnography.

The only methodology to have been substantially developed by higher education researchers of which I am aware, and already mentioned in the discussion of theory, is phenomenography. Phenomenography focuses on people's understandings or perceptions of particular phenomena of interest. Here, though, the honour has to be shared with education, as the originators of phenomenography were interested in teaching and learning in general, not just in higher education.

Phenomenography is probably better termed a research design, rather than a theory or a method, as it embodies both theoretical (i.e. there are a limited number of ways of perceiving a particular phenomenon) and methodological (typically the phenomenographic interview) perspectives. Even within higher education studies it is very much a minority interest, but it has been picked up and applied to some degree outside higher education (and education) as well.

\section{6) Some Institutional Manifestation.}

The final characteristic suggested by Krishnan is, as already noted, probably the most obvious, and probably the way in which most people would immediately think of disciplines: are there university departments, professors, degrees, journals and professional associations with 'higher education' in their titles? There are indeed all of these things.

The identification of 86 specialist academic journals focusing on higher education in 2016 has already been referred to (Tight 2018). This is undoubtedly an underestimate, as there is no definitive listing to check. While they are fewer in number, and similarly unlisted, there are also dozens of professional associations or societies focusing on higher education.

However, the presence of higher education studies within the university is both partial and particular. The Center for International Higher Education at Boston College, USA, maintains a very useful Worldwide Higher Education Inventory, which provides plentiful evidence on this characteristic (Rumbley et al. 2014). In 2014 it identified 277 graduate-level higher education programs (two-thirds of them in the United States) and 217 higher education research centres or institutes (50 in the USA, 44 in China and 18 in the UK) in 56 countries worldwide.

However, the programs identified are all graduate level; that is, they are postgraduate certificates (typically induction programmes taken by newly appointed academics), master's degrees or doctoral programmes. Higher education is rarely studied at first degree level, unlike most disciplines. And the institutional presence of higher education usually takes the form of research centres or institutes, rather than fully fledged academic departments.

In the United States the most common higher education studies presence is in the form of an institutional research office, charged with benchmarking the university's performance against its competitors, and more closely linked to the administration than to other university 
departments. In the UK or Australia this presence is most likely to be an academic development or teaching and learning centre, charged with improving the teaching performance of new and established academic staff. Typically, these will have fewer than 10 staff. The presence of a group of actively researching academic staff, focused on higher education studies, in a university or college - located in an education department or higher education research centre - is unusual.

Altbach comes up with the following summation: 'a total conservative estimate of professionals who are involved in research on higher education is probably more than 12,000 ' globally (2014, p. 15). While this is, indeed, a conservative estimate, and is out of date, the key point to emphasize for present purposes is that most of these people will only have a part-time commitment to researching higher education, and it may also be short-term. The number of full-time, career track higher education researchers is much smaller.

Higher education studies is unusual - as a field or discipline - in that those contributing are spread all over the academy, in all disciplines and often in the university administration as well. This does have some disadvantages, including lack of communication between those focusing on higher education studies and those focusing on discipline-based educational research (le Roux et al. 2019).

Higher education studies may, therefore, be described as an interdisciplinary field (or fields) of research, or, in Harland's (2012) words 'an open-access discipline'; in other words, interested parties from all disciplines are welcome to contribute.

\section{Conclusions}

I offer two alternative conclusions, though readers may wish to take up positions in between.

Higher education studies has a clear object of research - i.e. higher education - a major activity worldwide that is clearly deserving of and needing focused research. With a pedigree going back at least a century, and with a major expansion of interest in recent decades, higher education studies has accumulated a substantial body of specialist knowledge.

But here we diverge; either:

There are thousands of academics worldwide with an interest in higher education research, who are supported by learned societies and journals, many of them long established. As a social science, higher education studies makes use of the theories and methods used throughout the social sciences and has begun to develop and contribute its own (notably phenomenography). While higher education studies makes only limited use of specialist terminology, this makes it an 'open-access discipline' accessible to all interested researchers.

Higher education studies is, therefore, without doubt a discipline:

we would argue that although the discipline of higher education may seem to be less advanced down the discipline development pathway (if there indeed exists such a thing) than many other disciplines, it is nonetheless a well developed, multi-strand, complex collection of research agendas and people fulfilling these, and is in every respect a fullblown discipline. (Bath and Smith 2004, p. 13)

Or:

There are thousands of academics worldwide with an interest in higher education research, who are supported by learned societies and journals, many of them long established, but they are widely dispersed and marginal within universities and colleges, with few major 
departments or research centres focusing on higher education. As a social science, higher education studies makes use of the theories and methods used throughout the social sciences, but also often ignores them, and has made few original theoretical or methodological contributions of its own. This is reflected in higher education studies making only limited use of specialist terminology.

Higher education studies is not, therefore, a discipline but an interdisciplinary field of research. In the words of Altbach:

While higher education is not an academic discipline — the study of universities is an interdisciplinary endeavor based on the social sciences - it has emerged in a growing number of countries as a recognizable field of study, developing the standard accoutrements of any academic field. These include journals, publishers that focus on higher education, Web sites, national and international conferences, research centers and organizations, and others. While the development of the field is quite uneven globally, it now exists on all continents and in many countries. (2014, p. 12)

Or, to put it in a more developmental way:

Our findings suggest that, although higher education is not a distinct discipline, it has assumed some disciplinary characteristics - most notably the creation of a discourse community predicated on specialized knowledge and recurrent discursive strategies. (Kimball and Friedensen 2019, p. 1547)

The fairest conclusion, then, is probably that the jury is still out on the status of higher education studies. Much the same conclusion was reached nearly 50 years ago by Dressel and Mayhew (1974):

Higher education thus appears to be a field of study - ill-defined at the parameters - that is potentially useful in understanding many phenomenon [sic] and in preparing people for careers in higher education. But if the criteria suggested above are valid in defining a discipline, higher education has not yet attained that distinction. (p. 7)

Some 18 years later, Fulton came to a similar conclusion: 'Whatever its strengths, higher education studies as a discipline has not yet acquired the capacity to reproduce itself. This is surely a sign of immaturity' (1992, p. 1820).

It is important that the debate continues, however, because it is only by comparing itself to the exacting standards of established disciplines that higher education studies can hope to advance to disciplinary status in due course. Progress in this direction is largely in the hands of higher education researchers themselves, through demonstrating and communicating the worth and applicability of their research.

Open Access This article is licensed under a Creative Commons Attribution 4.0 International License, which permits use, sharing, adaptation, distribution and reproduction in any medium or format, as long as you give appropriate credit to the original author(s) and the source, provide a link to the Creative Commons licence, and indicate if changes were made. The images or other third party material in this article are included in the article's Creative Commons licence, unless indicated otherwise in a credit line to the material. If material is not included in the article's Creative Commons licence and your intended use is not permitted by statutory regulation or exceeds the permitted use, you will need to obtain permission directly from the copyright holder. To view a copy of this licence, visit http://creativecommons.org/licenses/by/4.0/. 


\section{References}

Abbott, A. (2001). Chaos of disciplines. Chicago: University of Chicago Press.

Altbach, P (2014) Knowledge for the Contemporary University: higher education as a field of study and training. pp. 11-21 in Rumbley, L, Altbach, P, Stanfield, D, Shimmy, Y, Gayardon, A de, and Chan, R, Higher Education: a worldwide inventory of research centers, academic programs, and journals and publications. Bonn, Lemmens Media, third edition.

Bath, D., \& Smith, C. (2004). Academic developers: An academic tribe claiming their territory in higher education. International Journal for Academic Development, 9(1), 9-27.

Becher, T. (1989). Academic tribes and territories: Intellectual enquiry and the cultures of disciplines. Milton Keynes: Open University Press.

Becher, T, and Trowler, P (2001) Academic Tribes and Territories: intellectual enquiry and the culture of disciplines. Buckingham, Open University Press, second edition.

Biglan, A. (1973a). The characteristics of subject matter in different academic disciplines. Journal of Applied Psychology, 57(3), 195-203.

Biglan, A. (1973b). Relationships between subject matter characteristics and the structure and output of university departments. Journal of Applied Psychology, 57(3), 204-213.

Cardenas, D. (2016). What is clinical nutrition? Understanding the epistemological foundations of a new discipline. Clinical Nutrition ESPEN, 11, e63-e66.

Chalofsky, N. (2007). The seminal Foundation of the Discipline of HRD: People, learning and organizations. Human Resource Development Quarterly, 18(3), 431-442.

Clegg, S. (2012). Conceptualising higher education research and/or academic development as 'fields': A critical analysis. Higher Education Research and Development, 31(5), 667-678.

Cobban, S., Edginton, E., \& Compton, S. (2007). An argument for dental hygiene to develop as a discipline. International Journal of Dental Hygiene, 5, 13-21.

Collins, R. (1998). The sociology of philosophies: A global theory of intellectual change. Cambridge: Harvard University Press.

Daenekindt, S., \& Huisman, J. (2020). Mapping the scattered field of research on higher education: A correlated topic model of 17,000 articles, 1991-2018. Higher Education. https://doi.org/10.1007/s10734-020-00500-x.

Davies, M., \& Devlin, M. (2010). Interdisciplinary higher education. In M. Davies, M. Devlin, \& M. Tight (Eds.), Interdisciplinary higher education: Perspectives and practicalities (pp. 3-28). Bingley: Emerald.

Davoudi, S., \& Pendlebury, J. (2010). The evolution of planning as an academic discipline. Town Planning Review, 81(6), 613-645.

Dressel, P., \& Mayhew, L. (1974). Higher education as a field of study. San Francisco: Jossey-Bass.

During, S. (2006). Is cultural studies a discipline? And does it make any political difference? Cultural Politics, 2(3), 265-281.

Fagerberg, J, and Verspagen, B (2006) innovation studies: An emerging discipline (or what)? A study of the global network of innovation scholars. Paper presented at the SPRU 40 th anniversary conference, University of Sussex.

Findlow, S. (2012). Higher education change and professional-academic identity in newly 'academic' disciplines: The case of nurse education. Higher Education, 63, 117-133.

Fulton, O. (1992). Higher education studies. In B. Clark \& G. Neave (Eds.), The encyclopedia of higher education (pp. 1810-1821). Oxford: Pergamon.

Furlong, J. (2013). Education: an anatomy of the discipline. Rescuing the university project? London: Routledge.

Gibbons, M., Limoges, C., Nowotny, H., Schwartzman, S., Scott, P., \& Trow, M. (1994). The new production of knowledge: The dynamics of science and research in contemporary societies. London: Sage.

Harland, T. (2012). Higher education as an open-access discipline. Higher Education Research and Development, 31(5), 703-710.

Heath, K. (1958). Is comparative education a discipline? Comparative Education Review, 2(2), 31-32.

Kimball, E., \& Friedensen, R. (2019). The search for meaning in higher education research: A discourse analysis of ASHE presidential addresses. Review of Higher Education, 42(4), 1549-1574.

Krishnan, A (2009) What are Academic Disciplines? Some observations on the disciplinarity vs. interdisciplinarity debate. Southampton, University of Southampton, National Centre for Research Methods.

Lawn, M., \& Keiner, E. (2006). Editorial. European Journal of Education, 41(2), 155-167.

Logan, F. (1963). Is there a discipline of art education? Studies in Art Education, 4(2), 10-14.

Loughran, J. (2009). Is teaching a discipline? Implications for teaching and teacher education. Teachers and Teaching, 15(2), 189-203.

Macfarlane, B. (2012). The higher education research archipelago. Higher Education Research and Development, 31(1), 129-131. 
Macfarlane, B., \& Grant, B. (2012). The growth of higher education studies: From forerunners to pathtakers. Higher Education Research and Development, 31(5), 621-624.

Makel, M., \& Plucker, J. (2014). Facts are more important than novelty: Replication in the education sciences. Educational Researcher, 43(6), 304-316.

Michailova, S., \& Tienari, J. (2014). What's happening to international business? University structural changes and identification with a discipline. Critical Perspectives on International Business, 10(1-2), 51-64.

Minton, P (1983) The Visibility of Statistics as a Discipline. American Statistician, 37, 4, 1, pp. $284-289$.

Nemetz, A. (1959). Religion as an academic discipline. Journal of Higher Education, 30(4), 196-200.

The New Shorter Oxford English Dictionary (1993) Oxford, Oxford University Press, two volumes.

Pearce, R. (1957). American studies as a discipline. College English, 18(4), 179-186.

Randel, W. (1958). English as a discipline. College English, 19(8), 359-361.

Ridder-Symoens, H de (ed.) (1992) A History of the University in Europe. Volume 1: Universities in the Middle Ages. Cambridge, Cambridge University Press.

Rollman, H. (2013). What's in a name? Reflections on what we call our discipline, and who gets to decide it. Journal of Gender Studies, 22(4), 444-451.

le Roux, K., Taylor, D., Kloot, B., \& Allie, S. (2019). Research on higher education: A perspective on the relations between higher education studies and discipline-based education research. Teaching in Higher Education, 1-15. https://doi.org/10.1080/13562517.2019.1634538.

Rumbley, L, Altbach, P, Stanfield, D, Shimmy, Y, Gayardon, A de, and Chan, R (2014) Higher Education: a worldwide inventory of research centers, academic programs, and journals and publications. Bonn, Lemmens Media, third edition.

Safarik, L. (2003). Feminist transformation in higher education: Discipline, structure and institution. Review of Higher Education, 26(4), 419-445.

Sarangapani, P. (2011). Soft disciplines and hard battles. Contemporary Education Dialogue, 8(1), 67-84.

Shahjahan, R., \& Kezar, A. (2013). Beyond the 'National Container'. Educational Research, 42(1), $20-29$.

Shumway, D., \& Messer-Davidow, E. (1991). Disciplinarity: An introduction. Poetics Today, 12(1), $201-225$.

Squires, G. (1992). Interdisciplinarity in higher education in the United Kingdom. European Journal of Education, 27(3), 201-210.

Sundberg, D. (2004). From Pedagogik to educational sciences? Higher education reform, institutional settings and the formation of the discipline of educational science in Sweden. European Educational Research Journal, 6(4), 393-410.

Tight, M. (2004). Research into higher education: An atheoretical community of practice? Higher Education Research and Development, 23(4), 395-411.

Tight, M (2012) Researching Higher Education. Maidenhead, Open University Press, second edition.

Tight, M. (2014). Discipline and theory in higher education research. Research Papers in Education, 29(1), 93110.

Tight, M. (2018). Higher education journals: Their characteristics and contribution. Higher Education Research and Development, 37(3), 607-619.

Turner, B. (2006). Discipline. Theory. Culture and Society, 23(2-3), 183-197.

Uljens, M. (2001). On general education as a discipline. Studies in Philosophy and Education, 20, $291-301$.

Publisher's note Springer Nature remains neutral with regard to jurisdictional claims in published maps and institutional affiliations. 